\title{
SIMULATION IN SAUDI HEALTHCARE: AN EMPIRICAL STUDY REVEALING THE CURRENT STATUS AND FUTURE PROSPECTS
}

\author{
A. Alrabghi* ${ }^{1 *}$
}

\section{ARTICLE INFO}

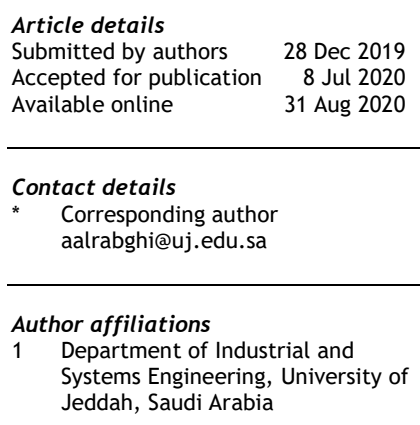

DOI

http://dx.doi.org/10.7166/31-2-2307

\section{ABSTRACT}

Providing efficient healthcare is more important today than ever before. Simulation is a well-established technique that has been used to understand and improve systems in various applications. It seems that simulation implementation in the healthcare industry is surrounded by a number of issues. Research on the subject has been mostly restricted to the analysis of academic literature, with a few industrial surveys. This empirical study contributes to our understanding of simulation application in Saudi healthcare services. The findings include an analysis of performance improvement methodologies currently in use, as well as simulation applications, barriers, and potential.

\section{OPSOMMING}

Doeltreffende gesondheidsorg verskaffing is belangriker as ooit vantevore. Simulasie is ' $n$ gevestigde tegniek wat al voorheen gebruik is om stelsels te verstaan en te verbeter in verskeie toepassings. Dit wil voorkom asof die implementering van simulasie in die gesondheidsektor met 'n aantal uitdagings gepaardgaan. Navorsing is grootliks beperk tot die ontleding van akademiese literatuur met ' $\mathrm{n}$ handjievol industriële meningsopnames. Hierdie empiriese studie dra by tot die verstaan van die toepassing van simulasie tegnieke in die gesondheidsorgsektor in Saoedi-Arabië. Die bevindings sluit in ' $n$ ontleding van bestaande vertoning verbeteringsmetodologieë en simulasie toepassings, grense en potensiaal.

\section{INTRODUCTION}

Providing efficient healthcare is more important today than ever before. The world population is growing and aging [1]. Global healthcare expenditure is increasing rapidly at a faster pace than the rest of the economy [2]. Researchers, engineers, and innovators are working on enhancing the current healthcare services by making them cost-effective and more accessible. The healthcare system in Saudi Arabia, in particular, is undergoing major reforms to restructure and privatise government hospitals [3], [4]. The move requires enhancing current efficiency levels, which is key to attracting local and international investors.

Predictive simulation is a well-established technique that has been used to understand and improve systems in various applications, such as business process engineering, scheduling, maintenance, renewable energy, and supply chain [5]-[7]. It is also seen as a key enabler of the transformation to the fourth industrial revolution [8]. Although simulation publications on healthcare are increasing [9], it seems that implementation in practice is low compared with other applications [10]. Research on the subject has been mostly restricted to the analysis of the academic literature, with a few industrial surveys limited to the US and Europe.

This study seeks to investigate the application of simulation in Saudi health services by exploring the nature and extent of simulation use, documenting the lessons learned from successful implementation, and identifying the obstacles that prevent healthcare organisations from realising the full benefits of simulation. 
In general, healthcare professionals are more familiar with simulation in the context of education, where it is used to train nurses and surgeons [11], [12]. However, in this paper the term 'simulation' will be used solely when referring to process simulation that is used to model healthcare operations.

\section{RELATED WORK}

There is a large volume of published studies on the application of simulation in healthcare. In fact, a recent survey of systematic reviews identified 37 review articles on the subject in the last three decades [9]. While the reader is referred to these publications for comprehensive reviews, we outline the key themes related to this research here.

\subsection{Volume and nature of simulation studies in healthcare}

A number of reviews have observed an exponential growth of publications in healthcare simulation over the years. Jun, Jacobson and Swisher [13] presented a review of papers using discrete event simulation (DES) in healthcare from 1970-1999, reporting an increasing trend of publications on using simulation to improve healthcare operations, including patient scheduling and admissions, patient routing and flow schemes, and scheduling and availability of resources.

A more recent review by Brailsford, Harper, Patel and Pitt [14] on simulation and modelling in healthcare found that, by 2009, around 30 new articles were being published in the field daily. The systematic review revealed that a wide variety of techniques are used to model healthcare, such as qualitative methods and spatial modelling. However, simulation studies have seen the most significant growth compared with traditional modelling techniques such as mathematical modelling or statistical analysis. Its use is also expected to continue to grow, particularly in modelling complex healthcare problems [15].

In an analysis of published research on applications of DES, Monte Carlo simulation and system dynamics, Mielczarek and Uziatko-Mydlikowska [16] found that DES is the most popular technique, representing around 75 per cent of published articles; and the largest area of application was operations of health and care systems, compared, for example, with disease prevention or extreme events planning. A recent review by Zhang [17] confirmed these findings. For example, DES is the most popular technique used to support bed management decisions and to model hospital-wide patient flow due to its ability to develop models rapidly, conduct strong analysis, and evaluate scenarios [18].

It is interesting to observe that most of the studies on modelling hospital scheduling and organisation were conducted in the US and the UK [19]. Brailsford et al. [14] reported that around 85 per cent of the publications originated in North America and Europe. This could indicate a lower adoption of simulation in healthcare elsewhere.

\subsection{Issues in implementation}

Early investigators voiced their concern over the level of the implementation of simulation results in healthcare [20]. This is because few researchers reported that the recommendations from the simulation projects were implemented and yielded positive results. With the aim of assessing the value of simulation to healthcare practice, Fone et al. [19] developed a rigorous methodology to assess the quality of simulation studies in the field, including model validity and results. They were not able to assess the value of modelling due to the minimal evidence of implementation outcomes. A possible explanation they provided was that publishing seems to precede implementation, due to the long period required to validate the model, implement the recommendations, and assess the results. In their later review, Brailsford et al. [14] confirmed that most of the published models were either suggested or conceptualised. Only a small proportion (around five per cent) were implemented.

Van Lent, Vanberkel, and Van Harten [21] reviewed papers that reported stochastic simulation applications in hospitals between 1997 and 2008. A survey was sent to the authors to enquire about the implementation and results of the simulation study. Around 44 per cent of the papers confirmed that results were at least partially implemented, although the total number of papers considered in the research ( 41 papers) seems small compared with the number of published articles in the field. Only seven projects reported having the performance measured before and after the simulation, which introduces challenges in quantifying the value of implementing simulation.

Jun et al. [13] argue that, although implementation levels might be low, conducting simulation studies provides other benefits. This includes better understanding the system of interest and developing decision- 
making skills [22]. Mielczarek and Uziatko-Mydlikowska [16] maintain that simulation does not necessarily specify a single solution to problems; it enhances the understanding of the problem and promotes discussion and debate between relevant stakeholders.

Academic articles and studies may not reflect an accurate level of simulation implementation in industry. Researchers may publish innovative models without necessarily requiring its application in practice. On the other hand, practitioners may choose to develop models to assist with daily decision-making without an interest in publishing their results. Therefore an understanding of the level of implementation calls for empirical evidence to establish the extent of simulation use and to explore its benefits and challenges.

\subsection{Industrial surveys}

Very little is currently known about simulation application in the healthcare industry, how it varies across different countries and environments, and what the main reasons behind its adoption are. Christy and Watson [23] conducted a survey of non-academic simulation users to examine the application of computer simulation in industry. Ninety members from the Operations Research Society of America (ORSA) and The Institute of Management Sciences (TIMS) participated in the survey. While the study provided insights into areas of application and popular programming languages, it was interesting to observe that simulation on medical applications and healthcare was not mentioned.

In an empirical study on the use of simulation in German healthcare institutions, Kirchhof and Meseth [24] investigated its role in decision-making and the potential reasons against its adoption. The study found that the level of simulation implementation is low, as the vast majority of participating institutions have not used it before. The main reasons behind the low adoption rate can be summarised as follows:

- Healthcare professionals are not aware of the benefits of simulation, and therefore it is not considered when evaluating decision-making tools.

- The costs associated with simulation, including software, hardware, training, model development, data collection, and use of consultants.

- $\quad$ A lack of the required simulation skills and capabilities.

- $\quad$ Simulation is seen as a slow decision-making tool, because developing the model and producing the required results requires a long time.

- In general, intuitive solutions are favoured over simulation.

To evaluate an interesting simulation initiative conducted by the National Health Services (NHS) in the UK, Brailsford et al. [25] reported the results of semi-structured interviews with employees who had been involved in the initiative. Scenario Generator $(S: G)$, a rapid simulation tool, was customised for healthcare by the SIMUL8 Corporation in partnership with the NHS. The software was made available for free to all interested NHS commissioning organisations, provided that they attended a one-day training session and had senior management approval. A simulation professional with NHS background delivered the training, and provided one year's telephone support to all the users.

Those who were actively using the software reported positive results in general, such as a good return on investment, compatibility with existing work practices, and seeing a clear advantage in simulation compared with the current decision-making practices. However, those who started implementing simulation, but decided not to take it any further, mentioned perception of usefulness as the main barrier. Other common barriers included:

- $\quad$ The current simulation skill base; there was lack of modelling awareness and skills.

- The long time required to develop a complete model with data.

- $\quad$ Time and capacity issues. Modelling adds to the load that healthcare professionals already have. Employing a dedicated analyst to collect and analyse data, develop models, and update them regularly was not an option for some participating organisations.

In general, these barriers are similar to those reported by Kirchhof and Meseth [24], except for the costs associated with simulation. This is probably because the NHS covered the costs in this initiative. On the other hand, the study revealed interesting insights into the elements that facilitated the adoption of simulation:

- $\quad$ The promotion of simulation by the NHS. It helped in raising awareness and ensuring credibility.

- $\quad$ Free training and support were cited as a key element for successful implementation. 
- The trainer had a medical background, which had a positive effect on many of the respondents.

- The benefit of visualisation and enhancing communications between decision-makers across disciplines was reported by many participants.

- $\quad$ Regulation was seen as a critical stimulus to adopting simulation. The World Class Commissioning Competency Framework includes predictive modelling as a key desirable competency.

\section{3}

\section{METHODOLOGY}

Semi-structured interviews were conducted to gain a deeper insight into the application of simulation in Saudi health services. The research methodology included the following steps:

- $\quad$ Developing the interview guide

- Identifying the participants

- Training interviewers

- $\quad$ Conducting interviews and collecting data

- Data analysis and group discussion

The guide was developed to structure the interview and allow for probing and asking for clarification whenever needed. The first section included questions on the participant and the healthcare facility, as well as the main approaches used to improve the operations, and whether simulation had been applied before.

The second section was designed to capture the simulation experience and results. The participant was encouraged to share details about at least one simulation project, including objectives, scope, key performance indicators (KPIs), timescale, key stakeholders, and simulation software. Other questions included the tangible benefits obtained from implementing simulation, the main challenges, lessons learned, motivation, and whether there was an intention to use simulation again in the near future.

This was followed by a question aimed at participants who had not used simulation before, to understand the main barriers limiting its adoption. All participants were asked whether they believed that simulation had the potential to improve operations at their organisations, and if they were interested in conducting simulation studies in collaboration with the university at their facilities.

The main target audience were managers in healthcare facilities, including hospital CEOs, quality/continuous improvement managers, emergency department managers, medical managers, and operations managers. Healthcare professionals who did not hold managerial positions were excluded. Hospitals and polyclinics of various sizes were considered, whereas clinics and smaller organisations were excluded. The city of Jeddah and its surrounding areas were the main geographical focus of the study. Jeddah is the second biggest city in Saudi Arabia, and it has the greatest number of hospitals and beds after Riyadh [26].

A training workshop was conducted for all interviewers participating in the research project, where the methodology and the interview guide were explained and discussed. Interviews were conducted in person with participants, and data was collected during the interview. Group sessions with all researchers followed to discuss the results of each institution individually, and to ensure that the required data was collected before conducting the analysis and producing the final results and conclusions.

\section{RESULTS AND DISCUSSION}

\subsection{Overview of results}

Data was collected via semi-structured interviews during September 2018. Interviews were conducted with a total of 47 professionals working in 24 unique healthcare facilities. As Figure 1 shows, most participants were from the specific targeted audience, such as general managers, or managers/directors of medical services, quality improvement services, support services, and the emergency department. Other participants were managers or assistant managers from different departments, such as histopathology and cytology, laboratory and blood bank, intensive care, and pharmacology. 


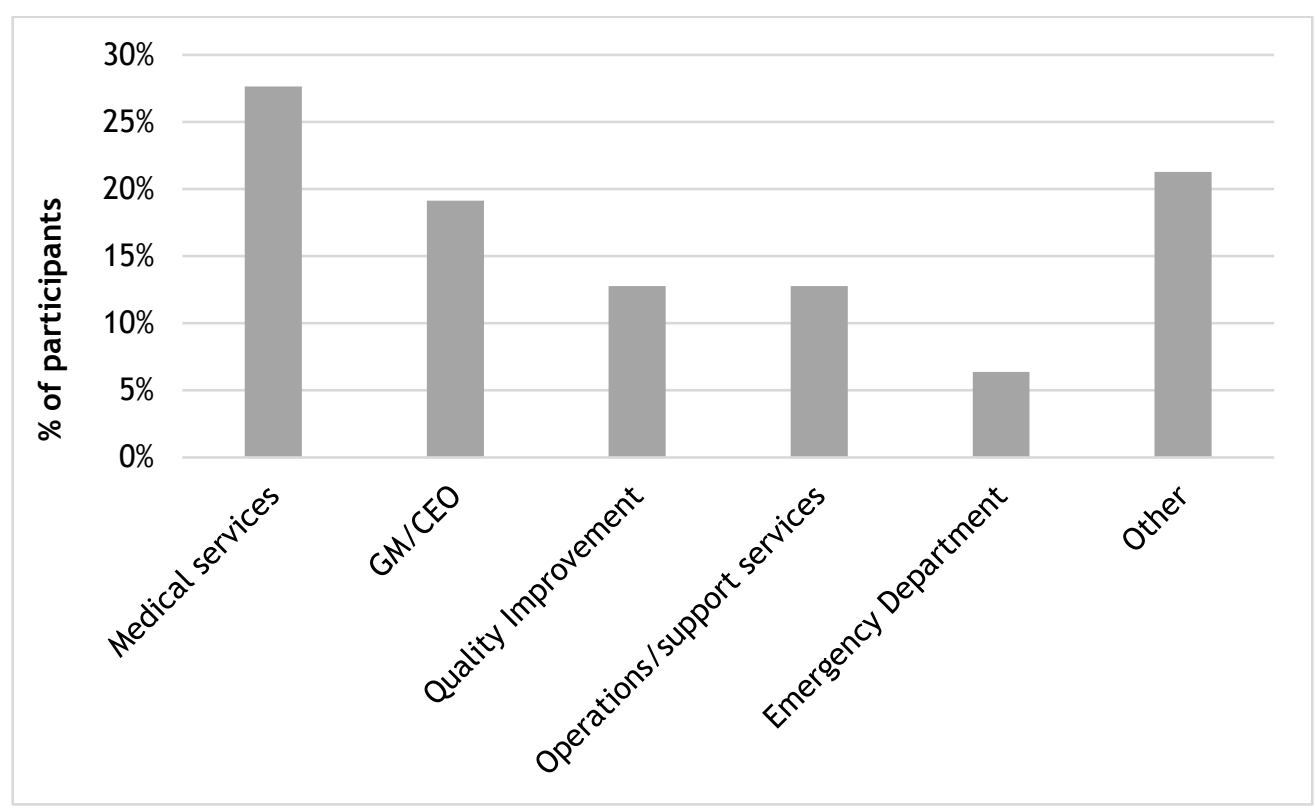

Figure 1: Positions of healthcare professionals who participated in the study (47 participants)

Participating managers worked in diverse organisations. Half of the organisations are funded by government, mostly belonging to the Saudi Ministry of Health. The other half are owned and run by the private sector. It is worth mentioning that, in general, 60 per cent of health needs in Saudi Arabia are covered by public healthcare facilities, while the rest are fulfilled by private hospitals and care centres [26]. Two-thirds of the organisations participating in the study were classified as hospitals, whereas the other third were polyclinics that included at least three specialised clinics. Around 37 per cent of the organisations are small with fewer than 100 beds, 38 per cent are medium-sized with 100 to 199 beds, and the remaining are large hospitals with a capacity of over 200 beds (see Figure 2).

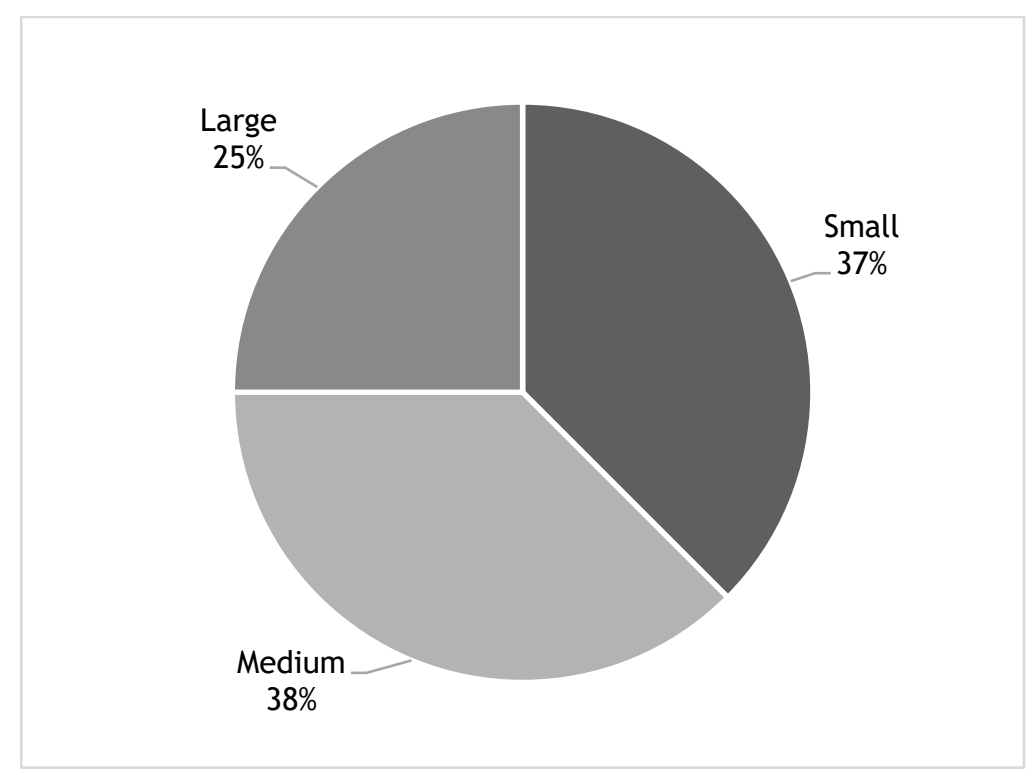

Figure 2: Participating healthcare organisations by size (24 organisations)

\subsection{Status of performance improvement in healthcare organisations}

Healthcare organisations continuously monitor their performance and strive to improve it. This section sheds some light on the most important operational performance indicators for the managers, and the methodologies they adopt to improve their performance. 
The most reported KPI was patients' waiting times in the healthcare facility (see Figure 3). Several managers described it as the main problem they face, as it significantly reduces patient satisfaction. The nature of healthcare provision means that patients are not always served in sequence according to their arrival times. In some instances, selected patients will be assigned higher priority due to their condition, which could mean an increase in waiting times for the rest of the patients. Even in areas where appointments are required and are fully scheduled in advance, the time of the consultation and care seem to vary widely, depending on the practice pattern of individual health professionals, the patient's preference for the type of care, and the condition of the patient.

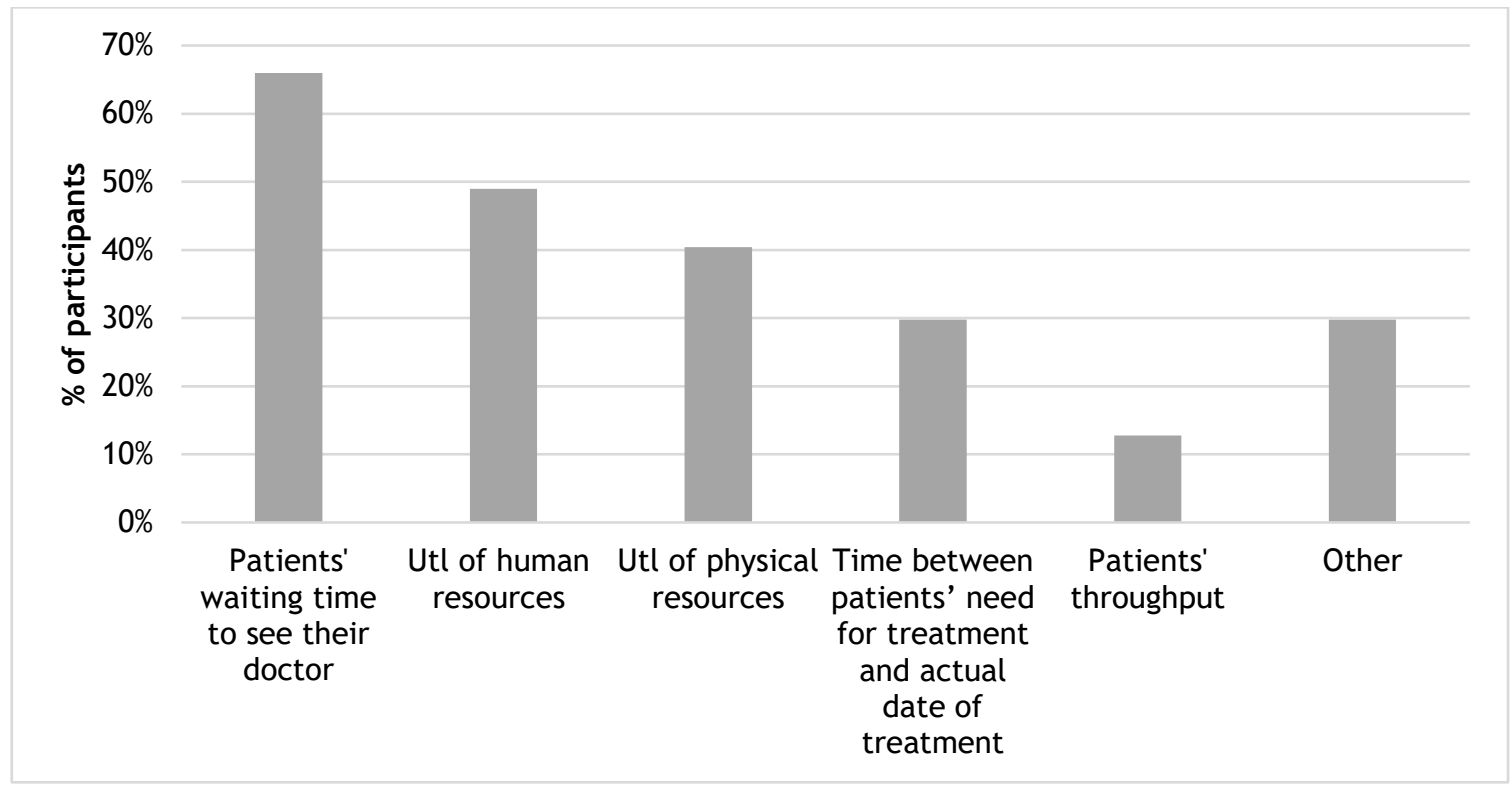

Figure 3: Operational key performance indicators (KPIs) in healthcare organisations

The second most reported KPI was the use of human resources such as doctors, nurses, and technicians, followed closely by the use of physical resources such as beds and equipment. Scheduling doctors' and nurses' shifts to maximise their use, while considering the bed occupancy rates amid the stochastic arrival patterns of patients, seemed to attract the attention of several managers. It was interesting to observe that patients' throughput was reported as a main KPI - mostly by private hospitals. It is seen as one of the factors that affect hospital income.

Other KPIs were reported, such as the bed-to-nurse ratio, the length of stay in emergency department, and the number of complaints/compliments received. In general, process simulation seems to be well-suited for most of the reported KPIs. In fact, studies that target these specific KPIs are among the most published in the field [16], [17], [27], [28]. Some participants mentioned generic areas such as patient safety, quality of care, patient satisfaction, clinical workflows, and patient engagement. These are likely to be areas where each is measured by one or more KPIs.

General quality improvement principles, along with mathematical models, were by far the most adopted methodologies to improve operational performance, as illustrated by Figure 4. Specific tools were mentioned, such as plotting data in graphs, performance comparison, statistical analysis, and root cause analysis. It was interesting to observe that only one hospital was implementing Six Sigma, while most of the remaining organisations seemed to implement basic analysis. Participants mentioned the compulsory quality accreditation by the Central Board for Accreditation of Healthcare Institutions (CBAHI) as a motive for adopting quality improvement principles. The accreditation promotes quality principles, such as being patient-centric and understanding the needs and expectations of patients [29]. This is consistent with the results in the UK, where legislation was one of the factors that facilitated the adoption of simulation as an improvement tool [25]. Another reason behind the popularity of quality improvement principles is that they can be understood and implemented by health professionals from different backgrounds without a need for extensive specialised training. 


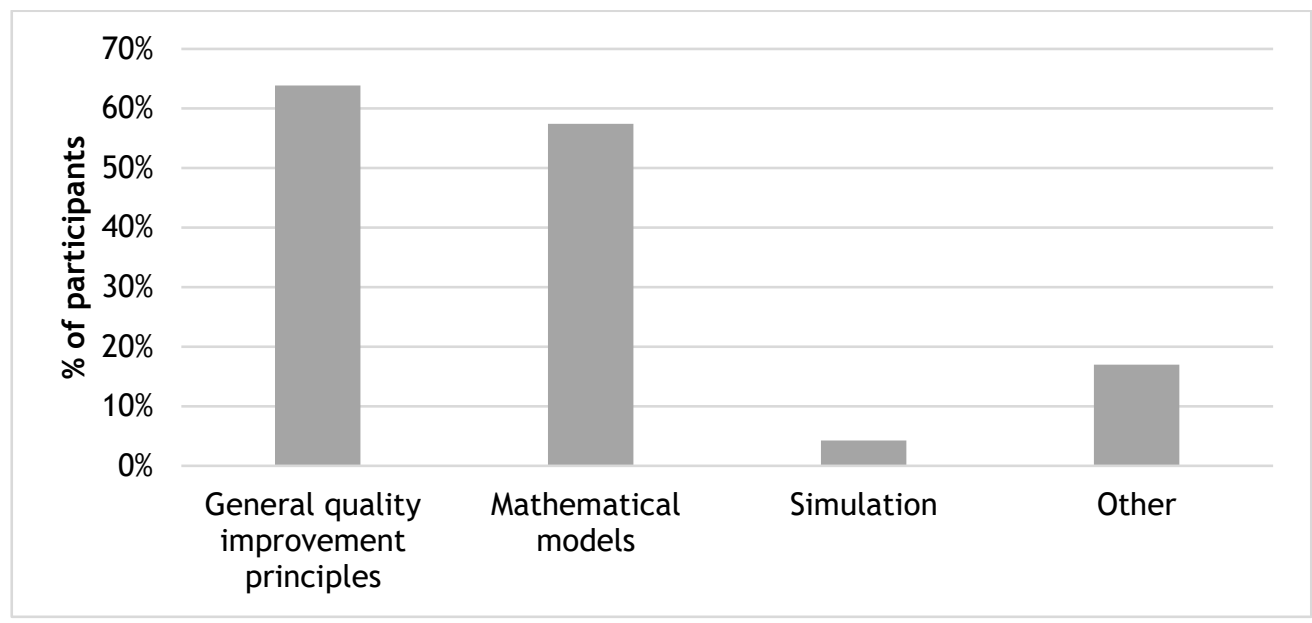

Figure 4: Tools/methodologies used to improve operations in healthcare organisations

A surprisingly small number of organisations adopt simulation. We shall investigate this later in the paper. Managers who reported other tools were mainly describing simple analysis, team meetings, and relying on experience. It is worth mentioning that managers in general seem to prefer simpler and faster analysis rather than using complicated and time-consuming studies. Several managers were satisfied with the results of basic analysis, in addition to relying on intuition and experience. A series of indirect questions were repeatedly asked by participants during the interviews: We see that other tools (for example, simulation) are more advanced and have better capabilities, but how long would it take to develop models and produce results? What is the cost of developing the required skills to use these tools?

Only a few managers expressed their displeasure with the methodologies currently being used. In general, these managers seemed to believe that the current methodologies were too simple, and fell short of providing the decision support they needed to improve performance.

\subsection{Simulation applications and experience}

Simulation applications in Saudi healthcare appear to be limited. Only two out of 47 participants indicated that they had used simulation before to improve their operations; both interviewees belonged to the same healthcare organisation (see Figure 5). In addition, simulation had been used only once recently, and was not being adopted as a part of the decision-making process in the organisation. This supports the finding in earlier studies that simulation was reported to be adopted mostly in the US and Europe, and much less elsewhere [14], [19]. For example, simulation seems more popular in Germany, where around 19 per cent of hospitals reported that they had used it before [24].

Have you used simulation before to improve operations in your organisation?

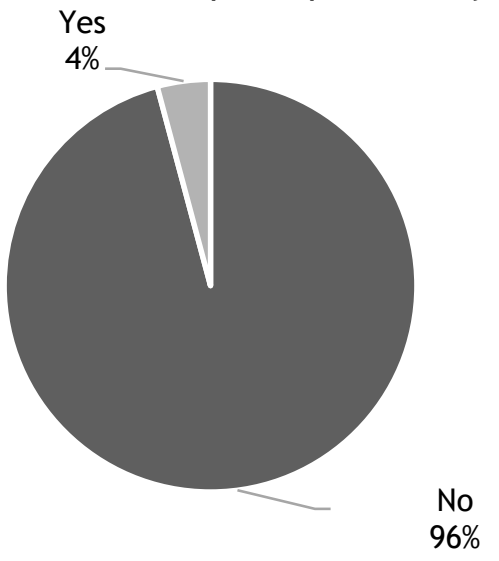

Figure 5: Simulation implementation in healthcare organisations 
The move to apply simulation was motivated by a desire to reduce the long patient waiting time in the psychiatric ward. The average waiting time for the patient from registration until being examined by the doctor was two hours. The management was investigating ways to reduce the waiting time to 45 minutes. Simulation was used to understand the current system better and to explore various configurations and policies. It was found that its use by staff could be improved. Also, all patients were made to join a single queue after registration, regardless of the type of service they needed. The optimum scenario consisted of filtering patients after registration, based on the service they needed.

A triage clinic was thus set up for two main tasks: filtering the psychiatric patients from those requiring medical examination by other healthcare professionals, and filtering patients coming for medicine refills. The simulation model was developed using Simio software. The project lasted for eight weeks, and resulted in reducing the average waiting time by 70 per cent to 35 minutes. The participants emphasised the ability of simulation to conduct experiments with high variabilities, and indicated their intention to use it to support future process improvements. These results reflect those of Brailsford et al. [25], who also found that, in general, those who actively use simulation indicate positive views on its advantages and return on investment.

\subsection{Simulation barriers and potential}

This section describes the reasons behind the low rate of simulation implementation and participants' reluctance to apply simulation to enhance their improvement efforts. Figure 6 presents the main barriers to simulation adoption. The most common barrier was the lack of awareness of process simulation and its capabilities as an improvement tool. Some managers indicated that this was the first time they had heard about simulation in this context. In fact, as the research team was required to ascertain that participants fully understood the concept of simulation as presented in this study, in some cases a substantial amount of time was spent at the beginning of the interview to explain the meaning and applications of simulation to participants. This may suggest that a significant proportion of managers in healthcare are not aware that simulation can model and improve operations, and so cannot be expected to implement it.

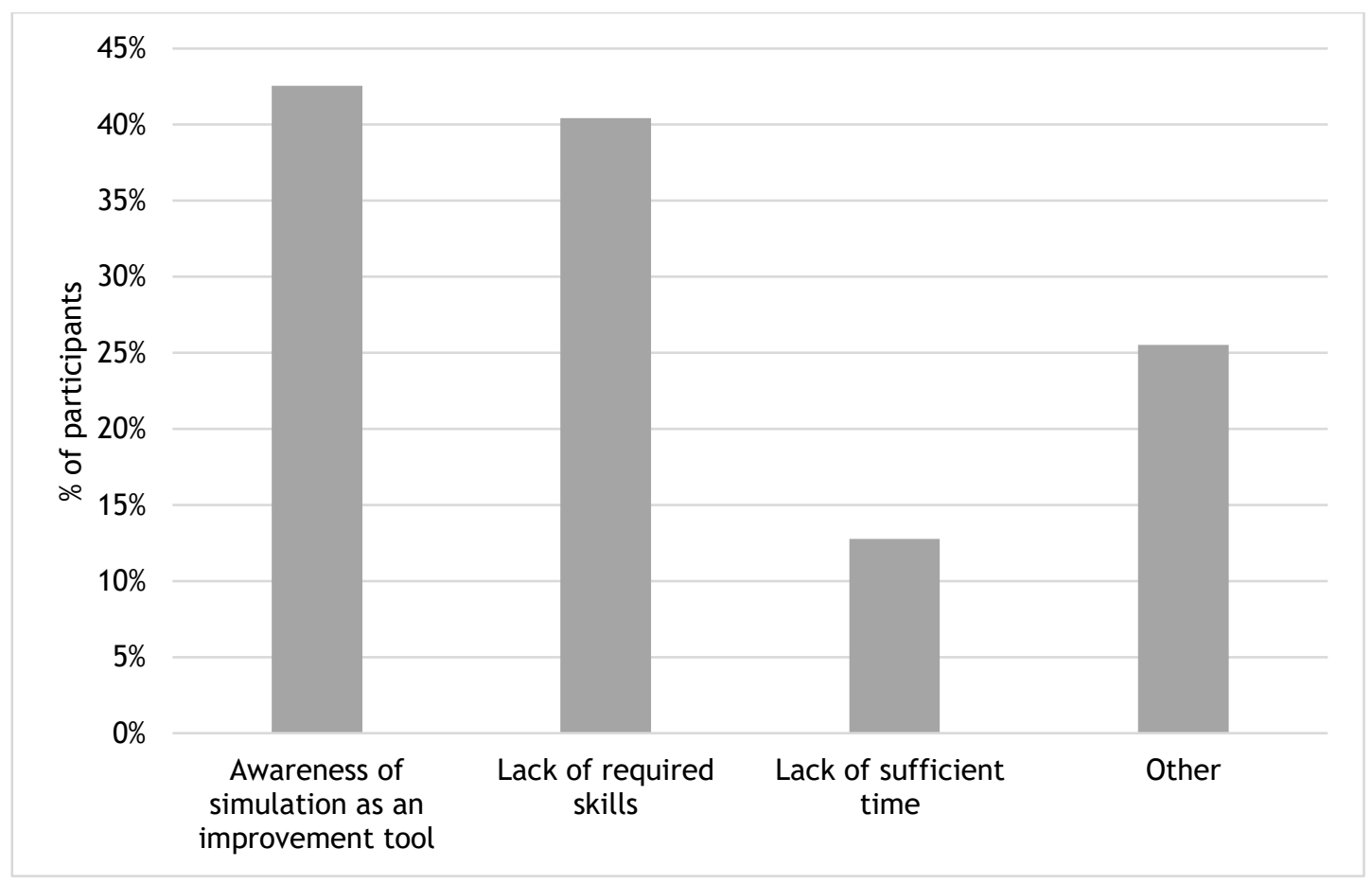

Figure 6: Main barriers to simulation adoption in healthcare organisations

The second most common barrier was the lack of the required simulation skills and expertise. As simulation is not one of the main methods to improve healthcare operations (see Figure 4), it is reasonable to assume that simulation capabilities are not available in most organisations. Some managers also seemed to believe that simulation studies cannot be conducted by their teams, but require experienced professionals or extensive education and qualifications. Managers thus seemed to prefer other improvement methods, such 
as statistics and quality improvement tools, where the required set of skills and experience were available within their teams.

Few of the participants indicated that one of the barriers to simulation adoption was the lack of sufficient time, either to conduct a simulation study or to learn how to develop simulation models. Some managers reported that they were under constant pressure to deal with daily operations and accreditation requirements. In addition, developing simulation models was seen as a lengthy process. Other managers reported that they did not see a need for simulation; and few of them reported cost as an obstacle to simulation implementation.

Although in different proportions, the main barriers expressed here are in agreement with those found in earlier studies, such as those conducted in the UK [25] and Germany [24]. Simulation awareness, skills, and qualifications are among the main challenges in the field [10], [30].

However, cost was reported as one of the main barriers in Germany, while only a few participants perceived it as a barrier in this study. While this could be because of differences in the work environment, a possible explanation is that, in this study, we adopted a semi-structured interview, in which the questions are openended, while the study mentioned above adopted a survey with closed-ended questions. Having an option for cost as one of the barriers might have caused some discrepancy in the results. Another possible explanation is that healthcare managers in Germany have more experience with using simulation, and therefore are more aware of its associated costs.

In general, managers perceived simulation positively, as can be seen from Figure 7 . More than 75 per cent chose 'strongly agree' or 'agree', indicating that they thought simulation had the potential to improve operations at their organisations. Some managers saw simulation as a new and promising technology compared with the current practices, and they expressed their general interest in applying new technologies. The concept of intelligent and powerful tools, as opposed to traditional methodologies, seemed appealing to several managers. Others indicated that they thought that simulation could find and evaluate solutions faster. Some managers believed that, if implemented, it could make a significant difference to the way decisions were made and communicated within the team.

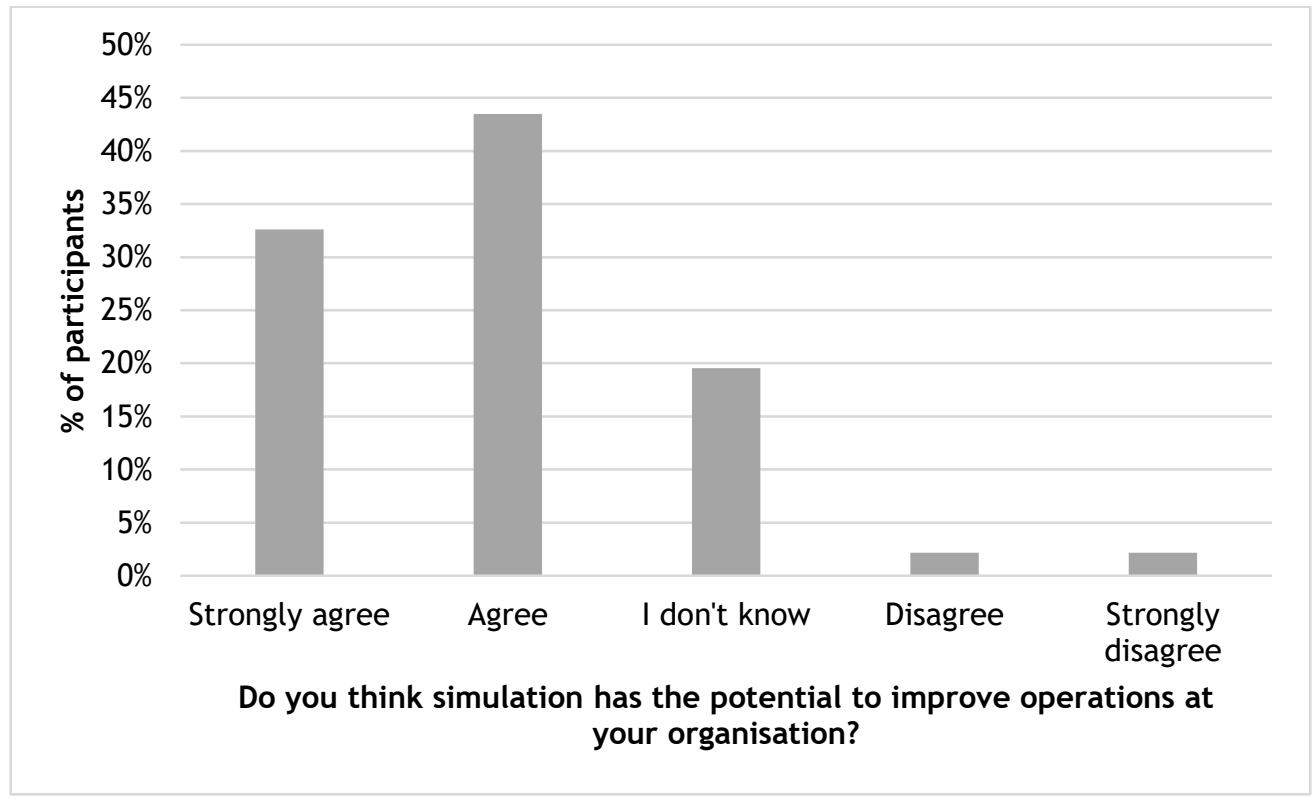

Figure 7: Perspective of participants on the potential of simulation

This outcome is contrary to that of German hospitals, where only 16 per cent of healthcare professionals stated that they would generally endorse a simulation project [24]. It seems that practitioners in Saudi Arabia are more open to new tools and methodologies, including simulation, to improve healthcare.

Some managers did not have sufficient simulation background; thus they could not comment on the possible value of simulation to their organisations. Others indicated that they needed to conduct a pilot study in 
their medical facility to be able to evaluate its potential benefit. Only a few managers did not believe that simulation had the potential to improve healthcare operations. One manager was strongly opposed to the idea that a non-healthcare professional would be able to improve healthcare operations. Others believed that such technologies would be more beneficial to larger hospitals than to their small organisations.

The positive perception of simulation was confirmed by the managers' acceptance of conducting simulation studies at their organisations. Seventy-five per cent of the managers were interested in forming a partnership with universities to investigate the use of simulation in supporting decision-making (see Figure 8). Several managers expressed their hope that they could continually develop their operations using the latest tools and technologies. Some managers see it as an opportunity for them to learn more about simulation and to have a simulation model developed for their facilities. Many managers indicated that it would be an experiment with little or no cost associated, assuming that trainees from the university would conduct most of the required tasks.

Would you be interested in forming a partnership with the university to conduct simulation studies at your organisation?

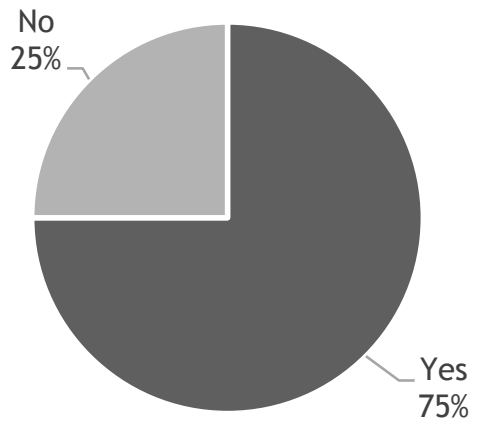

Figure 8: Willingness of participants to have simulation studies conducted in their organisations

Around a quarter of the participants were not interested in conducting simulation studies through the university. The organisation that was using simulation believed that it had the right set of resources to develop further simulation models. Some managers expressed their concern about the issue of data availability, which could make the simulation model of little value. Others believed that simulation would be beneficial in areas where there were big problems, such as overcrowding in some emergency departments.

\section{CONCLUSION}

Numerous studies have attempted to provide state-of-the-art simulation applications in healthcare. Most of the published research is limited to analysing academic articles, and it shows that the overwhelming majority of simulation applications are conducted in the US and Europe, with little known about its adoption elsewhere. In addition, only a few industrial surveys were reported, and their scope was also limited to the US or Europe. This empirical study contributes to our understanding of simulation application in Saudi healthcare services. Semi-structured interviews were conducted with 47 managers working in public and private healthcare facilities in Saudi Arabia.

The findings show that the current level of simulation implementation is very low. To improve operations, participants adopt alternative methodologies with which they are more confident, and which they perceive as faster and mostly sufficient for their purposes, such as general quality improvement principles and mathematical models. The main barriers that prevent the wider use of simulation are the awareness of process simulation as an improvement tool, followed by the lack of the required simulation skills and capabilities.

In general, the attitude towards simulation is encouraging. Those who applied simulation reported tangible benefits, and indicated their intention to use it to support future process improvements. Three out of four 
managers believed that it has the potential to improve operations at their organisations, and were willing to have simulation studies conducted at their facilities.

These findings provide insights to inform future research. A roadmap could be outlined to achieve a wider implementation of simulation in Saudi Arabia while considering the main stakeholders such as the Ministry of Health, accreditation bodies, private sector/investors, healthcare professionals, and the general population. Pilot simulation studies could also be conducted in selected healthcare facilities to determine its potential in the Saudi environment.

\section{REFERENCES}

[1] United Nations (UN). 2017. World population ageing 2017. Available online: https://www.un.org/en/development/desa/population/publications/pdf/ageing/WPA2017_Report.pdf

[2] Xu, K., Soucat, A., Kutzin, J., Brindley, C., Maele, N.V., Touré, H., Garcia, M.A., Li, D., Barroy, H., Flores, G., Roubal, T., Indikadahena, C., \& Cherilova, V. 2018. Public spending on health: A closer look at global trends. Geneva: World Health Organization. Available online: https: / /apps.who.int/iris/bitstream/handle/10665/276728/WHO-HIS-HGF-HF-WorkingPaper-18.3-eng.pdf?ua=1

[3] Hazzazi, H. 2018. Hospital privatization making headway. Saudi Gazette, 17-Jan-2018. Available online: https://saudigazette.com.sa/article/526392

[4] Rahman, R. and Alsharqi, O. Z. 2018. What drove the health system reforms in the Kingdom of Saudi Arabia? An analysis. The International Journal of Health Planning and Management, 34(1), pp. 100-110.

[5] Alrabghi, A. and Almaraashi, M. 2017. Investigating cleaning frequency of photovoltaic solar plants prone to soiling through stochastic simulation. International Journal of Simulation: Systems, Science and Technology, 18(2), pp. 4.1-4.5.

[6] Jahangirian, M., Eldabi, T., Naseer, A., Stergioulas, L. K. and Young, T. 2010. Simulation in manufacturing and business: A review. European Journal of Operational Research, 203(1), pp. 1-13.

[7] Alrabghi, A., Tiwari, A. and Savill, M. 2017. Simulation-based optimisation of maintenance systems: Industrial case studies. Journal of Manufacturing Systems, 44(Part 1), pp. 191-206.

[8] Alrabghi, A. 2018. Simulation based optimization frameworks as key enablers for the transformation to Industry 4.0. In The 48th International Conference on Computers and Industrial Engineering (CIE 48), Auckland, New Zealand, pp. 201.1-201.6.

[9] Salleh, S., Thokala, P., Brennan, A., Hughes, R. and Booth, A. 2017. Simulation modelling in healthcare: An umbrella review of systematic literature reviews. PharmacoEconomics, 35(9), pp. 937-949.

[10] Jahangirian, M., Naseer A., Stergioulas, L., Young, T., Eldabi, T., Brailsford, S., Patel, B., Harper, P. 2012. Simulation in health-care: Lessons from other sectors. Operational Research, 12(1), pp. 45-55.

[11] Kunst, E. L., Mitchell, M. and Johnston, A. N. B. 2017. Using simulation to improve the capability of undergraduate nursing students in mental health care. Nurse Education Today, 50, pp. 29-35

[12] Cook, D. A., Andersen, D. K., Combes, J. R., Feldman, D. L. and Sachdeva, A. K. 2018. The value proposition of simulation-based education. Surgery, 163(4), pp. 944-949.

[13] Jun, J. B., Jacobson, S. H. and Swisher, J. R. 1999. Application of discrete-event simulation in health care clinics: A survey. Journal of the Operational Research Society, 50(2), pp. 109-123.

[14] Brailsford, S. C., Harper, P. R., Patel, B. and Pitt, M. 2009. An analysis of the academic literature on simulation and modelling in health care. Journal of Simulation, 3(3), pp. 130-140.

[15] Ahmadi-Javid, A., Seyedi, P. and Syam, S. S. 2017. A survey of healthcare facility location. Computers \& Operations Research, 79, pp. 223-263.

[16] Mielczarek, B. and Uziałko-Mydlikowska, J. 2010. Application of computer simulation modeling in the health care sector: A survey. SIMULATION, 88(2), pp. 197-216.

[17] Zhang, X. 2018. Application of discrete event simulation in health care: A systematic review. BMC Health Services Research, 18:687.

[18] He, L., Chalil Madathil, S., Oberoi, A., Servis, G. and Khasawneh, M. T. 2019. A systematic review of research design and modeling techniques in inpatient bed management. Computers \& Industrial Engineering, 127, pp. 451466.

[19] Fone, D., Hollinghurst, S., Temple, M., Round, A., Lester, N., Weightman, A., Roberts, K., Coyle, E., Bevan, G. and Palmer, S. 2003. Systematic review of the use and value of computer simulation modelling in population health and health care delivery. Journal of Public Health Medicine, 25(4), pp. 325-335.

[20] Wilson, J. C. T. 1981. Implementation of computer simulation projects in health care. Journal of the Operational Research Society, 32(9), pp. 825-832.

[21] Van Lent, W. A., Vanberkel, P. and Van Harten, W. H. 2012. A review on the relation between simulation and improvement in hospitals. BMC Medical Informatics and Decision Making, 12:18.,

[22] Eldabi, T., Paul, R. J. and Taylor, S. J. E. 1999. Computer simulation in healthcare decision making. Computers \& Industrial Engineering, 37(1), pp. 235-238.

[23] Christy, D. P. and Watson, H. J. 1983. The application of simulation: A survey of industry practice. Interfaces, 13(5), pp. 47-52.

[24] Kirchhof, P. and Meseth, N. 2012. A survey on the use of simulation in German healthcare. In Proceedings of the 2012 Winter Simulation Conference (WSC), Berlin, Germany, pp. 1082-1091. 
[25] Brailsford, S. C., Bolt, T. B., Bucci, G., Chaussalet, T.M., Connell, N.A., Harper, P.R., Klein, J.H., Pitt, M. and Taylor, M. 2013. Overcoming the barriers: A qualitative study of simulation adoption in the NHS. Journal of the Operational Research Society, 64(2), pp. 157-168.

[26] Saudi Ministry of Health. 2017. Statistical Yearbook 1438H. Riyadh, Saudi Arabia: Saudi Ministry of Health.

[27] Rasheed, F. and Lee, Y. H. 2014. Enhancing performance of healthcare facility via novel simulation metamodeling based decision support framework. International Journal of Industrial Engineering: Theory Applications and Practice, 21(5), pp. 271-283.

[28] Ying, K.-C. and Kittipittayakorn, C. 2018. Combining discrete event and agent-based simulation for reducing draftees waiting time in physical examination. International Journal of Industrial Engineering: Theory Applications and Practice, 25(2), pp. 175-185.

[29] Almasabi, M. and Thomas, S. 2017. The impact of Saudi hospital accreditation on quality of care: A mixed methods study. The International Journal of Health Planning and Management, 32(4), pp. e261-e278.

[30] Fackler, J. and Spaeder, M. 2011. Why doesn't healthcare embrace simulation and modeling? What would it take? In Proceedings of the 2011 Winter Simulation Conference (WSC), Berlin, Germany, pp. 1137-1142. 